\title{
Evaluation of the accuracy of measuring the thickness of palatal tissue by different methods
}

\begin{abstract}
The main donor graft has the palatal mucosa as its main donor area. The thickness of the connective tissue is important in view of the fact that very thin grafts can fail. Although knowing the thickness of the palatal mucosa is important to improve the predictability of various surgical procedures, this assessment is ignored due to the lack of reliable planning methods for this purpose. In this study, an individual was evaluated making 3 markings on the palatal region, at a distance of $5 \mathrm{~mm}$ from the cervical palate of the first molar, second premolar and first premolar. To measure the markings, three methods were used: directly in the tomographic image (Group 1), in the superimposition of the computed tomography with scanning of the plaster model obtained from the patient's mouth (Group 2) and in the superimposition of the computed tomography and the scanning directly in mouth (Group 3 ), comparing with the gold standard using a needle with an endodontic stop at the three demarcated sites. Group 1 that represented the TCFC was the one that presented values closer to the gold standard values compared to the other two methods, and the first premolar and first molar regions were the regions that showed the least difference when compared to the gold standard. According to this study and its limitations, the group 1 method (CBTC) was the one that came closest to the gold standard in the three measured points, when compared with the other methods. Therefore, the use of CBTC to assess the thickness of the palatal mucosa is the most indicated.
\end{abstract}

Keywords: cone-beam computed tomography, palatal mucosa, measurement
Volume 4 Issue 2 - 2020

\author{
Francini Toito Ribeiro,' Milagro del Cielo \\ Chirinos,' Henrique Tuzzolo Neto, ,,2 Jorge \\ de Sá Barbosa,' Sandro Taira Camba, ${ }^{3}$ \\ Claudio Costa, ${ }^{2}$ Rodrigo Alves Ribeiro ${ }^{1,2}$ \\ 'Department of Dentistry, University Metropolitan of Santos, \\ Brazil \\ 2Department of Radiology, University of São Paulo, Brazil \\ ${ }^{3}$ Department of Dentistry, Paulista State University, Brazil
}

Correspondence: Rodrigo Alves Ribeiro, Department of Dentistry, University Metropolitan of Santos, Brazil, Email rodrigo.77@usp.br

Received: June 14, 2020 | Published: June 29, 2020

\section{Introduction}

The main donor graft has the palatal mucosa as the main donor area, widely used to increase the thickness of the alveolar ridge, to increase the dimensions of keratinized tissue around teeth and implants. ${ }^{1-6}$ Connective tissue grafts are also well recommended to improve the chance of covering gingival recession. ${ }^{7,8}$ The thickness of connective tissue is important in view of the fact that very thin or too thick grafts can lead to the failure of the procedure. ${ }^{9}$ Although knowing the palatal mucosa thickness would be important to improve the predictability of the result of various surgical procedures, this preoperative assessment of the donor area thickness is ignored due to the lack of reliable methods for this purpose.Applying conventional histology, studies were performed on cadavers to determine the thickness of the palatal mucosa ${ }^{10-12}$, we had a general idea of the best area for graft removal. However, each area and patient has variations in the amount available for removal. Invasive methods, such as the use of needles, ${ }^{2,13}$ endodontic files ${ }^{14}$ and periodontal probe ${ }^{15-19}$ have been described in the literature. These methods have a great disadvantage because they require the use of local anesthesia and are performed shortly before graft removal, not allowing an accurate pre-surgical planning of the procedure. The use of an ultrasound device is a non-invasive method, it has also been described in the literature, however, this method has a certain degree of complexity in obtaining results..$^{11,14,20,21}$

To analyze the maxillofacial region, conical beam computed tomography (CBCT) has been widely used., ${ }^{4,5,22} \mathrm{CBCT}$ technology is an essential tool in dentistry, offering high quality images to aid diagnosis. It has long been described that $\mathrm{CBCT}$ is not recommended for evaluation of soft tissues, being considered a tool to exclusively evaluate hard tissues of the maxillofacial complex. ${ }^{5}$ However, recently, information was obtained from evaluations that demonstrate that CBCT can be applied to visualize and measure soft tissues in the gingival region. ${ }^{22}$
In a recent retrospective study, images obtained by computed tomography (CT) beam were analyzed, and the thickness of the different regions of the palatal masticatory mucosa was determined with these images. ${ }^{23}$ However, the method has been described as unreliable using images to assess these measures.Due to the limited knowledge of the individual thickness and regional differences of the palatal mucosa, a method based on the CBCT technology has been developed to consistently visualize and effectively measure the dimensions of the palatal mucosa. ${ }^{23}$ The aim of this study was to evaluate the accuracy of measuring the thickness of palatal tissue by different methods.

\section{Material and method}

A male individual aged 64 years was evaluated. The individual sought the Implantology Service of the Metropolitan University of Santos to install implants in the posterior maxilla. The individual was molded with Hydrogum irreversible hydrocolloid (Zhermack, BadiaPolesine (RO), Italy) to make an individual tray on an acetate plate (Figure 1), where on this plate 3 markings were made on the palate, at a distance of $5 \mathrm{~mm}$ from the cervical palate of the first molar, second premolar and first premolar teeth, these holes were filled with zinc phosphate.An ORTHOPHOS XG 3D Cone-Beam Computed Tomography - PAN / TELE / TOMO (Sirona Dental Systems GmbH, Bensheim, Germany) was performed for evaluation and possible implant installation, the individual used the acetate plate with the markings to perform the tomography, as well as the lip retractor so that the lips and cheek do not disturb the taking of the image following the technique of Barriviera et al. (2009).A mold was made for making a model in special stone type IV Durone (Dentsply), which was scanned by the InEos Blue device (Sirona Dental Systems GmbH, Bensheim, Germany).

The individual was also scanned directly in the mouth using 
the Trios scanner (3Shape, HolmensKanal 7. 1060 Copenhagen K Denmark). To measure the markings, three methods were used, directly in the tomographic image (Group 1) (Figure 2), in the superimposition of the computed tomography and the scanning of the plaster model (Group 2) (Figure 3) and in the superimposition of the computed tomography and scanning in mouth (Group 3) (Figure 4). The Blue Sky Plan software (800 Liberty Drive Libertyville, IL 60045 United States) was used to overlay the images (Figure 5). During the implant installation surgery, the measurement considered in this study as the gold standard was performed, at the time of anesthesia, using the needle with an endodontic stop and with an individualized acetate tray in position, the punctures were performed in the places marked at $5 \mathrm{~mm}$ of the cervicals of the determined teeth (Figure 6). The needle with the obtained thickness was photographed and measured using the ImageJ64 image software (Wayne Rasband National Institute of Health, USA) (Figure 7).

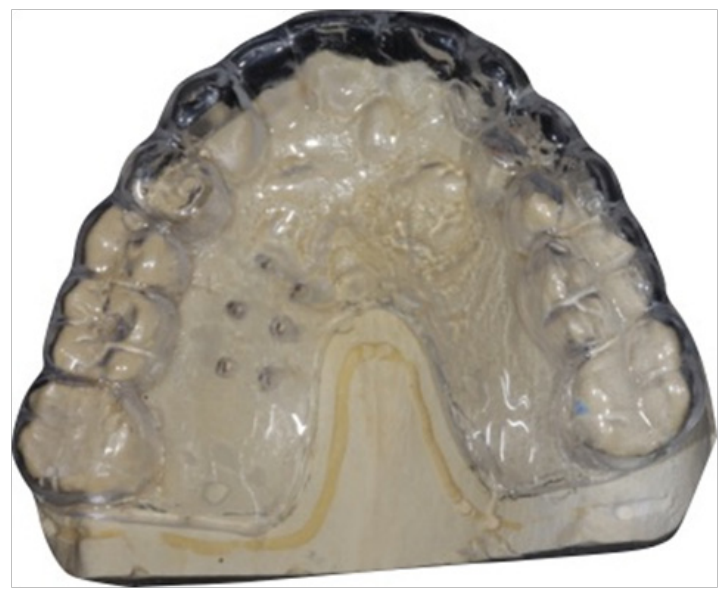

Figure I Acetate guide.

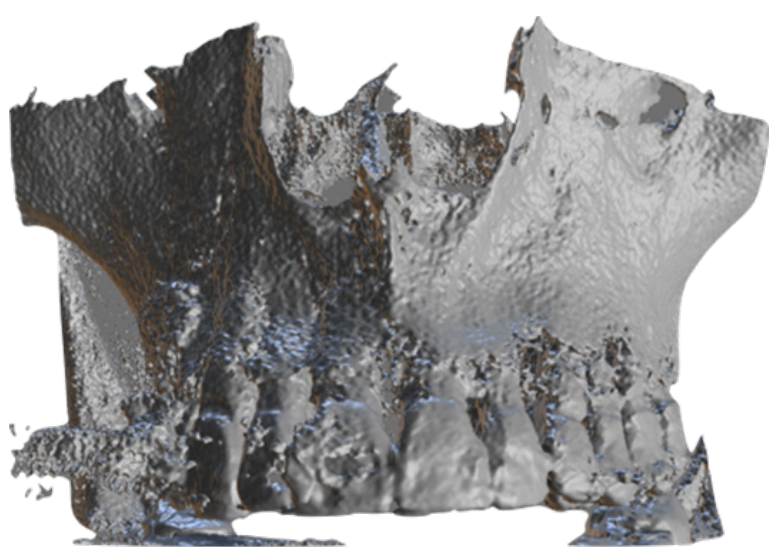

Figure 2 Tomography (Group I).

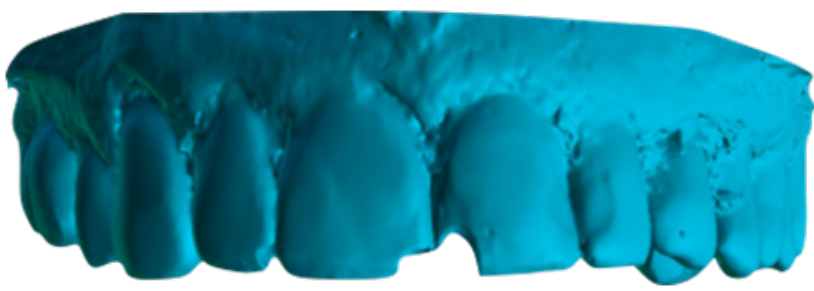

Figure 3 Plaster Model Scanning (Group 2).

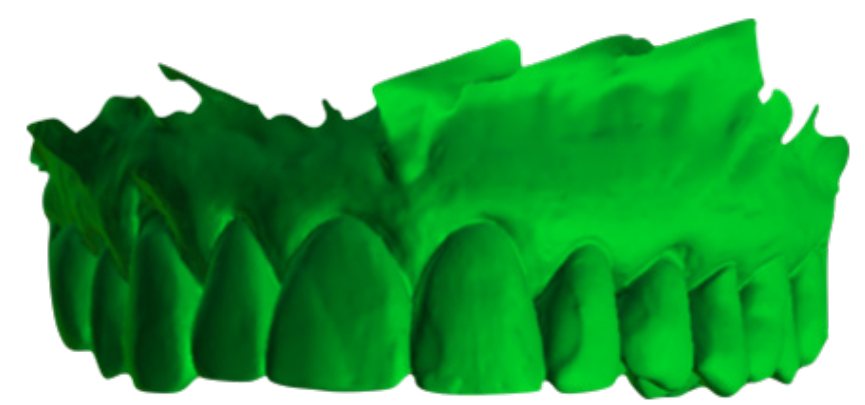

Figure 4 Oral scanning (Group 3).

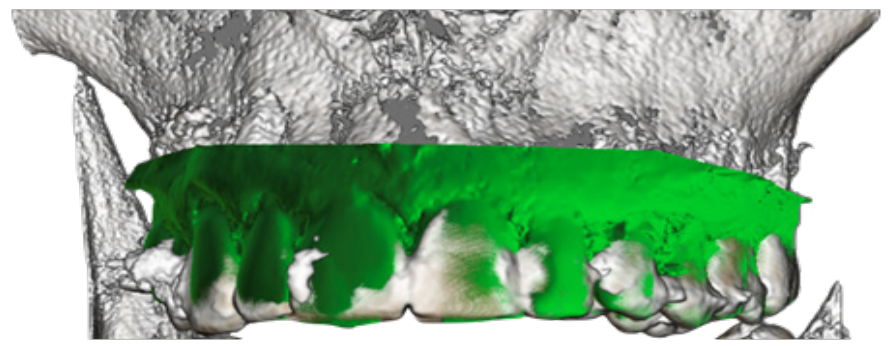

Figure 5 Alignment Tomography and scanning.

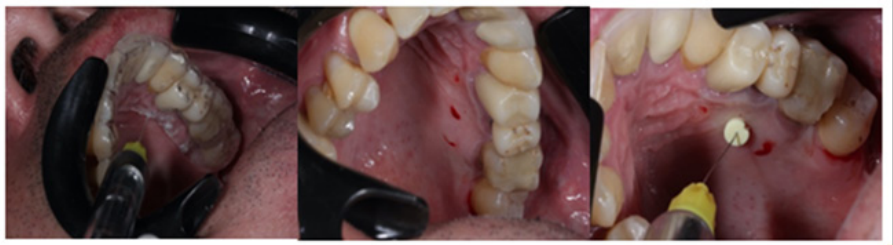

Figure 6 Scoring the locations determined in the Guide.

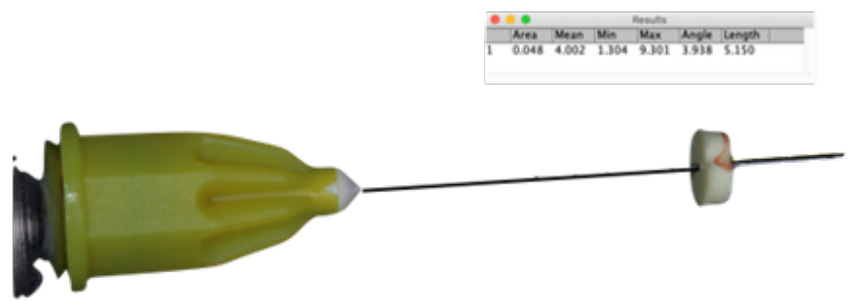

Figure 7 Gold Measurement Standard.

\section{Results}

Figure 8 demonstrates the evaluation of group 1 evaluation only CBCT Figure 9 demonstrates the evaluation of group 2 the overlapping of CBCT and the scanning of the plaster model and Figure 10 demonstrates the evaluation of group 3 the overlapping of CBCT and scanning of plaster mouth. In Table 1, group 1 was the one that presented values closer to the gold standard values.

In Table 2, the first Premolar and first Molar regions were the regions that showed the smallest difference when compared to the gold standard.

\section{Discussion}

The thickness of the palatal mucosa is characterized by variations that correlate with the dental regions, ${ }^{2,11}$ the second premolar region in this study presented the region with the largest thickness of the palatal mucosa when compared to the molar and first regions of pre- 
molar distance of $5 \mathrm{~mm}$ from the cervical of the teeth. Other studies characterize the region between premolars and canine as an area with better mucosa conditions, in addition to being thicker. ${ }^{15-19}$ The palatal mucosa is the main donor area for use in various procedures when soft tissue is used,,$^{1,3}$ there are several methods for assessing the amount of palatal mucosa invasively, using cannulas and probes, ${ }^{2}$ the noninvasive method using techniques based on computed tomography cone beam (CBCT) is being used to obtain high quality images of the palatal mucosa, and can be very reliable to visualize and measure the thickness of the mucosa. ${ }^{4,22,23}$ Other studies also confirm the results obtained in this study, the efficiency of the use of CBCT, allowing a clear visualization, making it possible to measure the dimensions and analyze the relationship between soft and bone tissue structures, assisting clinicians in planning preoperative. ${ }^{21}$

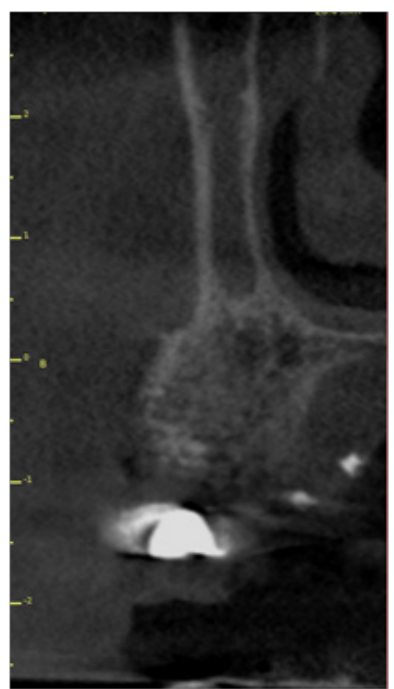

Figure 8 Group I.

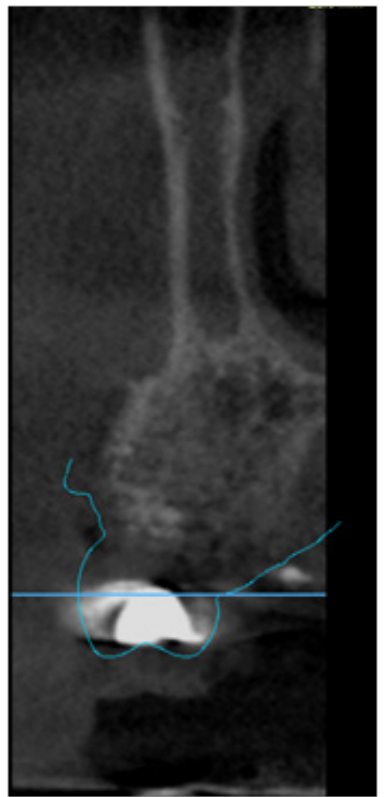

Figure 9 Group 2.

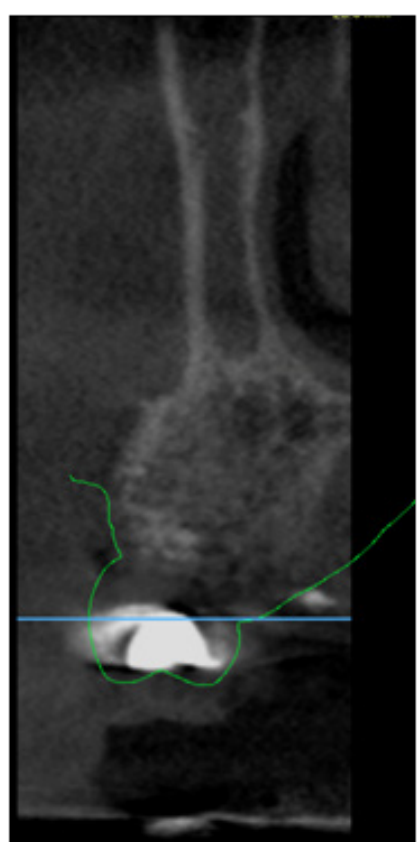

Figure 10 Group 3.

Table I Measurements of the Region evaluated in the determined Groups

\begin{tabular}{llll}
\hline & I Molar & $\begin{array}{l}\text { 2 } \\
\text { Premolar }\end{array}$ & $\begin{array}{l}\text { I } \\
\text { Premolar }\end{array}$ \\
\hline & $5 \mathrm{~mm}$ & $5 \mathrm{~mm}$ & $5 \mathrm{~mm}$ \\
Group I & 3,96 & 3,19 & 3,36 \\
Group 2 & 3,66 & 2,43 & 3,02 \\
Group 3 & 2,71 & 2,01 & 2,94 \\
Gold Standard & 4,8 & 5,69 & 4,2 \\
\hline
\end{tabular}

Table 2 Difference of Groups compared to Gold Standard

\begin{tabular}{llll}
\hline & \multicolumn{2}{l}{ Difference } & \\
& I Molar & 2 Premolar & I Premolar \\
\hline Group I & 0,84 & 2,5 & 0,84 \\
Group 2 & 1,14 & 3,26 & 1,18 \\
Group 3 & 2,09 & 3,68 & 1,26 \\
Gold Standard & 0 & 0 & 0
\end{tabular}

Evaluating the best way to select the location of the donor area and even projecting the thickness and quantity to be collected, it is possible to evaluate it through ultrasonic evaluation, ${ }^{20,21}$ but only mucosa. This study, on the other hand, proves the possibility of evaluating by means of cone beam computed tomography the alveolar bone set and the palatal mucosa structure. Several other studies have demonstrated this possibility. ${ }^{4,22,23}$ In the treatment of cleft palate, the main threedimensional techniques for assessing the soft tissues used are CT, CBCT, magnetic resonance imaging, stereo photogrammetry and scanning the laser surface. These techniques are mainly used for soft tissue analysis, bone graft evaluation and changes in the craniofacial skeleton. ${ }^{7}$ 
Scanning techniques in the mouth and digital dental molds have been transforming into a possibility of evidencing and determining digital palatal mucosa over time, the available evidence implies that 3D imaging methods can be used to assist in the assessment of mucosal soft tissue palatal. ${ }^{7}$ In this study it was found that CBCT presented results with values closer to the gold standard than those with overlapping digital images.

\section{Conclusion}

According to this study and its limitations, the group 1 method (CBTC) was the one that came closest to the gold standard in the three measured points, when compared with the other methods. Therefore, the use of CBCT to assess the thickness of the palatal mucosa is the most indicated.

\section{Acknowledgements}

None.

\section{Conflicts of interest}

Authors declare that there are no conflicts of interest.

\section{References}

1. Orban B, Sicher H. The oral mucosa. J Dent Educ. 1946;10:163-164

2. Schacher B, Bürklin T, Horodko M, et al. Direct thickness measurements of the hard palate mucosa. Quintessence Int. 2010;41:149-156.

3. Cortellini P, Tonetti M, Baldi C, et al. Does placement of a connective tissue graft improve the outcomes of coronally advanced flap for coverage of single gingival recessions in upper anterior teeth? A multicentre, randomized, double-blind, clinical trial. J Clin Periodontol. 2009;36:68-79.

4. Barriviera M, Duarte WR, Januario AL, et al. A new method to assess and measure palatal masticatory mucosa by cone-beam computerized tomography. J Clin Periodontol. 2009;36:564-568.

5. Cairo F, Pagliaro U, Niere M. Treatment of gingival recession with coronally advanced flap procedures: A systematic review. J Clin Periodontol. 2008;35:136-162.

6. Wennström, JL, Pini Prato, GP. Mucogingival therapy-periodontal plastic surgery. In: Lindhe, J, Karring, T \& Lang, NP (eds). Clinical Periodontology and Implant Destistry, 4th edition, 2003;576-631. Oxford, UK: Blackwell Munksgard.

7. Kuijpers MA, Chiu YT, Nada RM, et al. Three-dimensional imaging methods for quantitative analysis of facial soft tissues and skeletal morphology in patients with orofacial clefts: a systematic review. PLoS One. 2014;9(4):e93442.

8. Mörmann W, Schaer F, Firestone AR. The relationship between success of free gingival grafts and transplant thickness. Revas-cularization and shrinkage e A one year clinical study. J Periodontol. 1981;52:74-80.
9. Kydd WL, Daly CH, Wheeler JB III. The thickness measurement of masticatory mucosa in vivo. Int Dent $J$. 1971;21:430-441.

10. Uchida H, Kobayashi K, Nagao M. Measurement in vivo of masticatory mucosal thickness with $20 \mathrm{MHz}$ B-mode ultrasonic diagnostic equipment. J Dent Res. 1989;68:95-100.

11. Soehren SE, Alen AL, Cutright DE, et al. Clinical and histologic studies of donor tissues utilized for free graft of masticatory mucosa. $J$ Periodontol. 1973;44:727-741

12. Olsson $\mathrm{M}$, Lindhe $\mathrm{J}$, Marinello $\mathrm{CP}$. On the relationship between crown form and clinical features of the gingiva in adolescents. $J$ Clin Periodontol. 1993;20:570-577.

13. Eger T, Muller HP, Heinecke A. Ultrasonic determination of gingival thickness. Subject variation and influence of tooth type and clinical features. J Clin Periodontol. 1993;20: 839-845.

14. Studer SP, Allen EP, Rees TC, et al. The thickness of masticatory mucosa in the human hard palate and tuberosity as potential donor site for ridge augmentation procedures. J Periodontol. 1997;68:141-151.

15. Wara-aswapathi N, Pitiphat W, Chandrapho N, et al. Thickness of palatal mucosa associated with age. J Periodontol. 2001;72:1407-1412.

16. Stipeti CJ, Hrala Z, Celebi CA. Thickness of masticatory mucosa in the human hard palate and tuberosity dependent on gender and body mass index. Coll Antropol. 2005;29:243-247.

17. Kolliyavar B, Setty S, Thakur SL. Determination of thickness of palatal mucosa. J Indian Soc Periodontol. 2012;16:80-83.

18. Kuriakose A, Raju S. Assessment of thickness of palatal mucosal donor site and its association with age and gender. J Indian Soc Periodontol. 2012;16:370-374.

19. Müller HP, Schaller N, Eger T. Ultrasonic determination of thickness of masticatory mucosa: a methodologic study. Oral Surg Oral Med Oral Pathol Oral Radiol Endod. 1999;88: 248-253.

20. Savitha B, Vandana KL. Comparative assessment of gingival thickness using transgingival probing and ultrasonographic method. Indian J Dent Res. 2005;16:135-139.

21. Januário AL, Barriviera M, Duarte WR. Soft tissue cone-beam computed tomography: A novel method for the measurement of gingival tissue and the dimensions of the dentogingival unit. J Esthet Restor Dent. 2008;20:366-374.

22. Song JE, Um YJ, Kim CS, et al. Thickness of posterior palatal masticatory mucosa: The use of computerized tomography. $J$ Periodontol. 2008;79:406-412.

23. Scarfe WC, Farman AG, Sukovic P. Clinical applications of conebeam computed tomography in dental practice. $J$ Can Dent Assoc. 2006;72(1):75-80. 